\title{
REVIEW OF WANDERLUST: TRAVELS OF THE TAGORE FAMILY. TRANSLATED AND EDITED BY SOMDATTA MANDAL
}

\author{
HIMADRI LAHIRI \\ Department of English and Culture Studies, \\ University of Burdwan, \\ West Bengal. \\ hlahiri@gmail.com
}

Received: $30-03-2016$

Accepted: 29-08-2016

The book Wanderlust: Travels of the Tagore Family edited by Somdatta Mandal centres round the travel experiences of the members of the illustrious Tagore family of Jorasanko, Calcutta, whose contributions to the socio-cultural and religious developments of the country are etched in gold. Firmly grounded in the traditions of India, they also had considerable exposure to the Western ways of life and thought, and therefore had an easy access to the higher echelons of English society, both in India and in England. Wherever they went, whether in India or abroad, the family members were received with due respect. In the West they were considered to be the cultural ambassadors of their country. Bitten by the travel bug, they explored the world in search of pleasure, spirituality, knowledge, and, in some cases, business. Whether for pleasure, spiritual experience or business, they keenly observed the socio-cultural world around them and reflected on it with deep rationalist and humanist understanding. Their memoirs, travelogues, diaries or rough notes (taken during their journeys) bear evidence to their commitments to both traditional values and to the colonial modernity they were exposed to.

The book under review includes travel experiences of nineteen members of the Tagore household. Out of these nineteen writers, eleven were male and eight female. Bearing in mind that crossing the kala paani ("dark waters") was regarded as an act of inhibition, it arouses our curiosity as to how they, the women members in particular, responded to that aspect. The fact that there is a total absence of reference to, or comments on, this cultural 
inhibition is suggestive of their rationalist mindset. Women who travelled to the West, whether alone or with family members, displayed a rare sensitivity to the new spaces, natural and cultural environments, new flora and fauna, and relics of old historical monuments or events. In the context of the current academic interest in Indian women's early travels to vilayet ("the foreign land") - the corpus of critical writings and theories on travel had for a long time consisted mostly of accounts of the Western travellers travelling East with little attention paid to the reverse gaze - this book provides interesting facts and insights. It provides solid evidence of how both colonial and "alternative" modernities co-existed, and often coalesced, in the lives of the enlightened people of the time.

The book begins with the travels of Dwarakanath Tagore (1794-1846) and ends with those of Sumitendranath Tagore (1930-2006). It provides travellers' glimpses of the places they visited and the socio-cultural life of the people of both desh (the country) and videsh (foreign country) for about a century (from the mid-nineteenth century when Dwarakanath Tagore set sail for England in 1842 to the mid-twentieth century when Sumitendranath Tagore went to some parts of northern India at the age of about ten). The readers therefore get an almost uninterrupted view of their "lust" for travel during the period.

Writing about or editing a book like this involving authors of yore always poses an editorial challenge. Original manuscripts or their old published versions are usually not properly preserved; rummaging through the corpus of materials already archived is a huge task; the editor himself or herself sometimes has to translate original works. Added to these, in the present case, the task involves imaginatively reconstructing the travel experience of Prince Dwarakanath Tagore whose original English text is not extant. Neither could its Bengali translation, which was published in a journal of the time, be traced. The editor of this volume meticulously gathered facts and figures from different sources (mainly from the notes written by Dwarakanath's son Nagendranath who was part of the entourage) and reconstructed the journey in the form of a small biography. This is not an easy assignment to undertake if one keeps the question of authenticity in mind. This reconstructed essay, according to this reviewer, has certainly added value to the volume as the readers would wonder at the ease and comfort with which Dwarakanath Tagore rubbed shoulders with great men and women of his age (like the Prime Minister, the Duke of Wellington, the Duchess of Kent) at the Englishman's own home (or castle?) and had even met Queen Victoria. After his death at St. George's Hotel the Queen sent four royal pall-bearers to carry his body to the cemetery. Dwarakanath had also met the Pope at the Vatican and saw the frescoes at the 
Sistine Chapel. He hosted parties (one on a huge vessel on the river Thames) where literary figures like Charles Dickens, William Thackeray and Caroline Norton were present. This entry is thus of immense historical and literary importance. Apart from this narrative which she reconstructed and the one by Rathindranath Tagore ("My First Trip to the USA") which was written originally in English, all other entries have been translated by the editor of the volume. The compilation assumes importance from this perspective as well. Satyendranath's entry "Bombai Sahar" (The City of Bombay), however, does not, according to this reviewer, justify its inclusion. It does not seem to have anything to do with "wanderlust" as it is a mere historical, geographical and social account of the city. Although the editor includes this to "give a taste of his writing" (49), it cannot be considered a travelogue in any sense of the term. Originally published in Balak (which in Bengali means "the young boy"), a Tagore household journal, it is an essay that offers information and was originally meant to educate young minds.

Besides Prince Dwarakanath's account, there are some more accounts of foreign travels in the volume. Jnanadanandini Devi's "Purba Katha ar Bilater Katha" (Prelude and about Vilayet), Rabindranath Tagore's "Samudra Pari" (Crossing the Ocean) and "Londone" (In London), Sobhanasundari Devi's "Ranakshetre Bangamahila" (A Bengali Lady in the Battlefield), Rathindranath Tagore's "My First Trip to the USA," Soumyendranath Tagore's "Europer Pathe" (Travel to Europe) are interesting narratives of the authors' travels to the West. Debendranath Tagore's "Moulmin Bhraman" (Travel to Moulmin, 1950) offers a different taste. It recounts his admiration for the beautiful exotic places in Burma. He describes a mountain cave known as the Farm Cave where he went by steamer. It was a wonderful journey on the river Ataran. He comments on the active role women played in public spaces, expresses admiration for Burmese hospitality and describes their social habits and religious rites. This journey to Moulmin, it may be noted, was more the result of a whimsical decision than one of careful planning. This seems to have been, to a certain extent, in the blood of the members of the clan because the same thing also happened in the case of Swarnakumari Devi who "suddenly one evening ... decided that I would leave [for Prayag] tomorrow" (103). This propensity for taking instinctive decisions may be attributed to their aristocratic class background where whimsicalities, and even eccentricities, were not unusual traits in characters. But this at the same time draws our attention to the notion that travellers of the earlier centuries were "exceptional" people, exceptional in the sense that they differed from the normal run of social creatures in their daring, adventurous spirit, in their ability to 
take risks of life and reputation, in their whimsicalities and caprices - in short, in their "waywardness". Susan Bassnett observes that "[o]ne consistent line through discussions of women travellers is the notion that they were somehow exceptional....in an age when relatively few people travelled at all, the idea of a woman traveller was something of a novelty" (228-9). She further comments that women travellers are "categorised as doubly different: they differ from other, more orthodox, socially conformist women, and from male travellers who use the journey as a means of discovering more about their own masculinity" (226). But the novelty in the case of women travellers whose narratives have been included in this volume also consists in how they, confined as they were, despite being in an enlightened household, responded to the outside world, both inside the country and outside, and to other cultures, including the one that colonised them. Women's entries in the volume speak highly of their intellectual competence in encountering "other" cultures and "other" histories.

It is also interesting to note how the daughters and the daughters-in-law of the enlightened Tagore family responded to the social prejudices and how they articulated their strong opinion against instances of gender prejudice. Jnanadanandini Devi, for example, mentions in "Purba Katha ar Bilater Katha" how even in the Tagore family "[d]aughters-inlaws were not loved till they gave birth to sons" (94) or Swarnakumari Devi in "Prayag Jatra" (Trip to Prayag) speaks of the 'problem' of a young girl's propensity to laughing too much (113-4) which was considered to be a non-feminine trait. Sarala Devi's conviction of her own right to approve of the suitable person she was to marry speaks highly of her feminine agency (309). Besides, the way many of the women of the family ventured into the new, unknown places abroad, often alone, and encountered challenges speaks highly of their education, courage, knowledge and intelligence. One can hardly forget how Sobhanasundari Devi faced the trial of proving the authenticity of her passport at the French port of Dieppe ("Ranakshetre Bangamahila" 311-2). She herself, as it turned out, was the Bangamahila in a different ranakshetra that the title of her entry refers to (A Bengali Lady in the Battlefield). Contributions by the women members of the Tagore family thus form an important component of the volume. They offer not only descriptions of the places they visited or the "unusual" scenes they witnessed (the snowfall, for example in London in Jnanadanandini Devi's travelogue) but also a clear picture of the gender prejudice they had to encounter and the gender boundaries within which they had to operate. Soudamini Devi's kindheartedness, her openness of mind, her ability to reach out to people irrespective of their religious identities, her analytical insights into social evils like begging are revealed in her two 
travelogues in the book - "Vizigapattam,' and "Tirtha Darsan" (On a Pilgrimage). Their intellectual ability (e.g. acquisition of a language like French) is also apparent in the pieces like the one by Jnanadanandini Devi. Swarnakumari Devi's "Prayag Jatra" (Trip to Prayag) displays a rare sense of wit and humour. All these represent women's perspectives on the home and the world.

The pieces offer a picture of how the modes and modalities of travel were changing. They provide descriptions of journeys by river and sea, on the land, through different landscapes and hillscapes in India and abroad, journeys by horse-drawn carriages, steam ships, trains and even electric train - the last named in Kshitindranath Tagore's "Sahityokarer Urojatra: Ekti Kheyal" (208). Kshitindranath came across it in Bombay (now Mumbai) in 1928. The paraphernalia of travels - e.g. packing which may give rise to "box-phobia" (170), all the noises, anxieties and excitements associated with it, travel to the stations or the ferry ghat or the port, as the case may be - are described in minute details in one entry by Rabindranath Tagore. The pieces also evoke a strong sense of cosmopolitanism evident in the way the members of the family were eager to establish contacts with people of all cultures and religions. One should be thankful to the editor of this volume for bringing together such rich materials within the two covers of this book. The only thing that has caused irritation to this reviewer is the poor proofreading (instances of which are scattered throughout the book) and sometimes bad formatting (e.g. 218). The underlined sectional headings in some entries like "Bombai Sahar" and "Purba Katha ar Bilater Katha" look, graphologically speaking, a bit odd. The publishing house, it seems, is in need of professional editors and proof-readers.

\section{WORKS CITED}

BASSnEtT, SusAn (2002). "Travel Writing and Gender." The Cambridge Companion to Travel Writing. Ed. Peter Hulme and Tim Youngs. Cambridge: Cambridge UP: 225241.

MANDAL, SOMDATTA (2014). Translator and Editor. Wanderlust: Travels of the Tagore Family. Kolkata: Visva-Bharati.

HIMADRI LAHIRI received his PhD degree from the University of Burdwan, West Bengal, India where he now serves as Professor of English. His areas of interest are postcolonial literature, Asian American writing and Indian writing in English. 